\title{
PEDAGOGIA E EPISTEMOLOGIA JURÍDICAS: PROCURANDO NOVOS RUMOS
}

\author{
PEDAGOGY AND EPISTEMOLOGY LEGAL: \\ LOOKING FOR NEW DIRECTIONS
}

PAULO FERREIRA DA CUNHA Prof. Catedrático da faculdade de Direito da Universidade do Porto, Portugal pfcunha@direito.up.pt

\section{SUMÁRIO}

1 POR UMA INICIAÇÃO AO DIREITO; 2 POR UM DIREITO INTERDISCIPLINAR; 2.1 Escolhos Autognóticos da Juridicidade; 2.2 Interdisciplinaridade(s); 2.3 Interdisciplinaridade e Direito; 2.3.1 Justaposição de saberes; 2.3.2 Hibridização de Saberes; 2.3.3 Perspetivação Jurídica Holística; 2.3.4 Interdisciplinaridade Jurídica Crítica; 2.3.5 Interdisciplinaridade Exógena e Interdisciplinaridade Endógena; 2.3.6 Novos Rumos; REFERÊNCIAS.

\section{POR UMA INICIAÇÃO AO DIREITO}

Não se tem curado a sério da Pedagogia Jurídica num sentido de Liberdade e de Formação, embora muito nos últimos tempos se faça por uma pedagogia rígida, burocrática, autoritária, disfarçada de eficácia, técnica, ciência e em todos os países colonizados e fascinados se invoque a excelência do exemplo estrangeiro. Por vezes bem menos recomendável que a tradição nacional... Mas há casos e casos, claro.

Os aprendizes de juristas precisam de ser acolhidos por Themis e por lustitia, conviver com Hermes, e assim familiarizar-se com o Direito não de uma forma meramente discipular perversa ${ }^{1}$ mas fazendo jus à universitas magistrorum et scolarium na sua verdade de iguais e de diferentes.

\footnotetext{
${ }^{1}$ Louvaminhando um cappo di scuola e fazendo carreira pelo mimetismo face a tudo o que diz, escreve, ou mesmo, v.g., veste, ou aos tiques que eventualmente tenha: trejeitos, bordões de linguagem, etc. - tudo é copiado no mais servil mimetismo pelos muchachos e muchachas.

REDESG / Revista Direitos Emergentes na Sociedade Global - www.ufsm.br/redesg v. 3, n. 1, jan.jun/2014
} 
É assim necessário uma iniciação ao Direito bem diversa dos rituais hoje instituídos (obviamente estamos a falar de uma outra praxe académica). Desde logo, há que advertir que uma iniciação ao saber jurídico não é uma simples disciplina de Introdução ao Direito. Ou, pelo menos, se o for também um pouco, não o será da mesma maneira. E também não é uma Introdução ao Estudo do Direito, como é óbvio. É, realmente, algo de diverso. 0 que não quer dizer que esses outros "géneros" e disciplinas do Direito não sejam muitíssimo importantes, embora nem sempre devidamente prezados e assumidos como o que realmente são (ou deveriam ser).

Uma introdução ao Direito é, em geral, exclusivamente para caloiros. Uma iniciação ao saber jurídico é para estes, e é para todos os que dela precisem, e o reconheçam. 0 mesmo será dizer: todos os que para ela tenham vocação. Eventualmente já formalmente juristas. Eventualmente não juristas.

Há muita gente formada (melhor dizendo, "encartada") em Direito e que, contudo, não deve ter prestado grande atenção às suas aulas de introdução ao Direito, ou de introdução ao estudo do Direito. Pelo menos alguns conceitos e ideias fundamentais não transparecem na sua prática. Pena é, também, que muitas vezes essas aulas não sejam dadas com empenhamento (não ousaríamos a alguns pedir paixão, sabendo o que sabemos, desde logo com Warat, sobre o sufocar dos sentimentos pelos juristas comuns - e, pelo contrário, da importância jurídica do sentimento ${ }^{2}$ ) e sejam meras primeiras partes, partes gerais, ou amálgamas de outros setores da enciclopédia jurídica, designamente quando os seus docentes as consideram menores face a

\footnotetext{
${ }^{2}$ Por exemplo, atentemos neste texto fundamental, que não se aplica somente à mediação, a nosso ver: “Para mediar, como para viver, é preciso sentir o sentimento. 0 mediador não pode se preocupar por intervir no conflito, transformá-lo. Ele tem que intervir sobre os sentimentos das pessoas, ajudá-las a sentir seus sentimentos, renunciando a interpretação.Os conflitos nunca desaparecem, se transformam; isso porque, geralmente, tentamos intervir sobre o conflito e não sobre o sentimento das pessoas. Por isso, é recomendável, na presença de um conflito pessoal, intervir sobre si mesmo, transformar-se internamente, então, o conflito se dissolverá (se todas as partes comprometidas fizerem a mesma coisa). 0 mediador deve entender a diferença entre intervir no conflito e nos sentimentos das partes. 0 mediador deve ajudar as partes, fazer com que olhem a si mesmas e não ao conflito, como se ele fosse alguma coisa absolutamente exterior a elas mesmas. Quando as pessoas interpretam (interpretar é redefinir), escondem-se ou tentam dominar (ou ambas as coisas).Quando as pessoas sentem sem interpretar, crescem. Os sentimentos sente-se em silêncio, nos corpos vazios de pensamentos. As pessoas, em geral, fogem do silêncio. Escondem-se no escândalo das palavras. Teatralizam os sentimentos, para não sentilos. O sentimento sentido é sempre aristocrático, precisa da elegância do silêncio. As coisas simples e vitais como o amor entende-se pelo silêncio que as expressam. A energia que está sendo dirigida ao ciúme, à raiva, à dor tem que se tornar silêncio. A pessoa, quando fica silenciosa, serena, atinge a paz interior, a não violência, a amorosidade. Estamos a caminho de tornarmo-nos liberdade. Essa é a meta mediação." - WARAT, Luis Alberto - O Ofício do Mediador, Florianópolis, Fundação Boiteux, 2004, p. p. 26.
}

REDESG / Revista Direitos Emergentes na Sociedade Global - www.ufsm.br/redesg v. 3, n. 1, jan.jun/2014 
especialidades mais rentáveis e prestigiadas... fugindo sempre para dar introduções específicas a essas partes e não ao Direito em geral.

Ao pensarmos que em um ou outro reduto entre nós e sobretudo (com gáudio e sem complexos) noutras latitudes as introduções ao Direito são verdadeiras portas abertas para o conhecimento integral do Direito, em clave metodológica mas sobretudo filosófica, e os seus manuais são lidos e relidos dentro e fora das universidades (pense-se nas mais de 50 edições da Introducción al estudio del Derecho de García Máynez, no México - e contudo falecido em $1993^{3}$ ) não podemos deixar de observar como, pensando alegremente que estamos evoluídos, afinal não pelo que de nosso fazemos, antes por reverenciarmos o que vem de fora (de certos horizontes do que está fora), nos encontramos num ocaso profundo de cultura jurídica.

Mais ainda que distraídos ou olvidados do que aprenderam (ou não chegaram a aprender nas disciplinas introdutórias - íamos a arriscar que toda a Licenciatura é uma grande introdução ao Direito), muitos, ainda cursando Direito, e outros já por essas provas tendo passado, nunca foram verdadeiramente ver o que estava por detrás da cortina do feiticeiro (mágico) de Oz. Ficaram fascinados com a grandiosidade da Teoria Geral de um Estado que não existe, deleitaram-se com a filigrana conceitual do crime, da culpa e da pena, acreditaram que a vida social e os negócios tinham a sua quintessência no direito privado, e de tanto terem que decorar conceitos, teorias, artigos e sentenças, esqueceram-se da razão por que deveriam ter ido para o curso de Direito, e o domínio de tão áridas, complexas e vastas matérias consolou-os de terem esquecido a Justiça.

Em conclusão: há muitos a quem falta e faltou uma autêntica Introdução ao Direito. Mais do que se pensa. Mas muitos mais são os que, quedados na exterioridade de um Direito e de uma Justiça vendados, nunca foram mais longe, nunca verdadeiramente tomaram posse do Direito, nunca olharam a Justiça face a face, e nos olhos. Por muito que possam ter epítetos de juristas ou de profissões jurídicas em ostentatórios cartões de visita.

Por isso é que a Filosofia do Direito e outras matérias humanísticas e críticas, que são a via de acesso iniciático mais simples a esse auêntico Saber Jurídico, irritam tantos: é que elas recordam (como que numa reminiscência platónica) o outro Direito, o direito arquetípico mas também o direito que está aí, na rua, e quantas vezes, também (agora numa recordação da

\footnotetext{
${ }^{3}$ Cf. FIX-FIERRO, Héctor - “Presentación” de Eduardo García Máynez (1908-1993). Vida y obra, de Imer B. Flores, México, Universidad Nacional Autónoma de México, 2007, p. XI.

REDESG / Revista Direitos Emergentes na Sociedade Global - www.ufsm.br/redesg v. 3, n. 1, jan.jun/2014
} 
memória pessoal) os sonhos abandonados pela rigidez dos códigos e as veredas da chamada vida prática.

É que a Filosofia do Direito e as demais matérias que obrigam não só a pensar, mas também a pensar criticamente, por detrás das cortinas, não são (não devem ser: há filosofias do Direito bem comportadas que confundem e enredam como a pescadinha-de-rabo-na-boca e são, afinal, como dizia, noutro contexto Vergílio Ferreira, “refeições requintadas em que não se come nada e só se saboreia" - e se chegassem algumas a ser isso!) saberes abstratos e fora da realidade. Esse é um estigma traiçoeiro que é lançado contra a função eminentemente prática destas matérias. Na verdade, alguns lançam o ferrete do teoricismo e do desinteresse da Filosofia do Direito para a vida prática precisamente porque temem o seu enorme e evidente potencial prático. No dia em que se souber mais Filosofia do Direito, em que mais criticamente se pensar e repensar o Direito, e em que tal seja feito por muitos, alguns institutos, práticas, instituições até, não poderão descansar na rotina e na tradição: terão de mostrar o que valem, para que servem, por que devem manter-se, ou então como podem mudar, ou acabar. É um risco muito grande pensar criticamente...

Entretanto, ninguém que se não haja realmente apropriado dos instrumentos desconstrutores, críticos e criativos das humanidades jurídicas, a começar pela Filosofia do Direito, poderá realmente dizer-se jurista, e portanto iniciado na arte boa e équa.

Pode ser-se um poço sem fundo de conhecimentos positivos e até teóricos do Direito, pode até saber-se muito das opiniões de velhos e novos filósofos do Direito sobre Direitos concretos ou o Direito em geral. Mas há um espírito que é necessário conquistar pelo esforço pessoal, lendo nas entrelinhas, vendo os avessos do Direito. Retirando as suas vendas, e retirando as vendas próprias.

Durante muitos anos pensámos que esse trabalho, a nosso ver então algo de radicalmente pessoal, não deveria ser sugerido de fora, nem explicitamente. Seria preciso que cada um, com o tempo e a experiência, fosse alcançando a subtileza das coisas por si (como aliás foi o nosso caso, ajudado pelos livros e mestres que a vida nos foi felizmente colocando no caminho). Descobrir o que está por detrás do discurso legitimador do Direito não se encontra, em absoluto, expresso na Introdução ao Direito (uma das melhores, sublinhe-se) de Baptista Machado. Mas só 
o título é uma ponta do véu que se descobre: Introdução ao Direito e ao Discurso legitimador ${ }^{4}$. Que prodigiosa audácia, para aqueles tempos, naquele contexto!

Com o decurso dos anos, não só em relação ao Direito mas para muitas coisas da vida, fomos entendendo que a capacidade de ler os subentendidos, mesmo as ironias, se encontra cada vez mais debilitada entre nós. A denotação, agigantada certamente pela sociedade do espetáculo ${ }^{5}$ e pelo bombardeamento das declarações políticas (que pouco dizem, em geral, num exercício iterativo da função fática da linguagem) perturbou as conotações, que se nos furtam e nós nos furtamos a elas.

Aquilo que era pressuposto ser conhecido à entrada na Universidade não mais o é. Em muitos casos, começa a construir-se a casa não pelo telhado, mas com base em alicerces pouco sólidos, e com várias estacas ou pilares evidentemente em falta.

E uma das competências (vamos sacrificar às modas do "eduquês" e chamar-lhes assim mesmo: afinal a denotação é também uma questão de moda, e de imposição do poder de palavras; palavras são poder, expressam poder) que está visivelmente em falta é a hermenêutica. Seria necessário um longo treino de convívio hermenêutico com grandes e bons textos para que os estudantes soubessem...ler. E cada vez mais não se sabe ler, nem ouvir, nem entender, claro... $\mathrm{O}$ que se repercute no não se saber também estruturar um pensamento $\mathrm{e}$ expressá-lo, por escrito e oralmente (não, obviamente, o mero fazer-se entender na vida quotidiana, que parece requerer umas 500 palavras apenas e nenhuma subtileza). E isso não termina por milagre quando se obtém um doirado diploma com fitas rubras.

Claro que as Faculdades de Direito em que temos lecionado, pelo mundo fora, têm desses problemas muito mais atenuados, porque nelas entra a fina-flor dos estudantes. Mas mesmo assim não estão impermeáveis totalmente à tendência.

Por estas e por outras razões é que cada vez mais começamos a condescender com a ideia de que, se quisermos realmente ser entendidos, temos que dizer o que queremos que seja entendido, e da forma mais clara possível. Embora haja coisas que não se podem exprimir em 500 palavras simples e com estruturas gramaticais elementaríssimas. Esse é também um dos aspetos do drama. Além disso, há coisas que ditas perdem o sentido, ou, pelo menos, a

\footnotetext{
${ }^{4}$ BATISTA MACHADO, João - Introdução ao Direito e ao discurso legitimador, reimp., Coimbra, Almedina, 1985.

${ }^{5}$ DEBORD, Guy - La société du spectacle, Paris, Gallimard, 1992.
} 
profundidade... Mas se não forem ditas há quem também nunca as consiga descobrir. Portanto, mesmo com riscos, desde logo de incompreensão, dizer é preciso.

E essa é, afinal, a razão de ser deste artigo: dizer (na verdade, apenas ir dizendo) algo do que é ocultado, mas deveria ser como que obviamente subentendido.

\section{POR UM DIREITO INTERDISCIPLINAR}

\subsection{Escolhos Autognóticos da Juridicidade}

Perante os múltiplos ardis que se urdem em torno do seu estatuto e praxis éticoepistémica (porque de tal junção se trata, nem de puramente apenas ética ou somente epistemologia), a condição do Direito é complexa e vulnerável. A fachada de magna ciência, aureolada de ética e armada de poder, tem obviamente pés de barro, e oculta uma "retaguarda" ou um "miolo" de crise e crítica6.

Bastaria recordar o que sucede no terreno jurídico com o que para algumas epistemai seria o principium sapientiae: a própria questão de uma definição, descrição, conceito ou noção de direito (não se fale sequer de “ideia de Direito” aqui). Como é sabido, as mais canónicas das definições ou processos enunciativos delimitadores similares (incluindo tópicos tais como “conjunto de normas”, “imposição coativa”, “origem estatal”, e "finalidade de pacificação social" ou afim) estão em profunda crise, até pelo facto de que todos os traços pretensamente caracterizadores do Direito comportarem significativas exceções - pelo menos.

E a alternativa aproximação à essência (no fundo é isso que estes procedimentos realmente buscam desvendar e desvelar) da juridicidade por via da Justiça, considerando que o Direito é o seu objeto e, como dizia uma glosa medieval, dela deriva como um filho de sua mãe, insistindo no constans et perpetua voluntas suum cuique tribuere - que é uma proposição cheia de potencialidades - não deixa de comportar também os seus escolhos, sobretudo pela banda do titularismo jurídico, quando reduz o suum de cada um a uma lista apenas um pouco mais vasta de fontes de direito que a lei.

\footnotetext{
${ }^{6}$ BAPTISTA PEREIRA, Miguel - Crise e Crítica, in "Vértice“, vol. XLIII, n. ${ }^{\circ} 456 / 7$, Coimbra, SetembroDezembro de 1983, p. 100 ss..

REDESG / Revista Direitos Emergentes na Sociedade Global - www.ufsm.br/redesg v. 3, n. 1, jan.jun/2014
} 
Esta dificuldade de base em delimitar-se e compreender-se por parte do Direito em geral ganha sigificado também numa outra questão autognótica qualificativa muito simples, mas muito significativa: que tipo de episteme é o Direito? Os mais tradicionalistas, conservadores, tanto os rigidamente agelastas quanto os menos reflexivos, inclinam-se para que o Direito seja uma ciência. Mas há os que o consideram uma arte. Certamente poderá haver elementos de uma e de outra, e também de ténica (a técnica, aliás, é um saber fazer comum tanto à primeira como à segunda). Mas a questão é saber o que o Direito será mais... para o que ele preferencialmente tenderá.

Temos sérias dúvidas que se possa considerar ciência um saber não só tão radicalmente atravessado pela ideologia (mas muitas ciências sociais o são), como sobretudo tão dependente do virtuosismo teórico-prático dos seus intérpretes. A hermenêutica jurídica, hoje cada vez mais e justamente vista como interpretação-criação-aplicação do Direito, parece-nos ter na interpretação musical o seu modelo, e por vezes interpretação mais livre, como a de Jazz.

Em vez de uma definição rigorosa e rígida de Direito, teremos certamente duas tópicas jurídicas: uma tópica ontológica para o sollen, e uma tópica sociológica para o sein, sendo que esta última será certamente a mais usada. Em lugar de um Direito brilhando ao sol com a sua couraça científica, um Direito mais noturno e lunar, com as vestes mais modestas da arte, e arte muitas vezes de artífice, que tem de comportar o rasgo do virtuosismo, mas também o ostinato rigore de que falava Leonardo Da Vinci ${ }^{7}$.

Digamos que múltiplas focalizações ou perspetivações do Direito nos levam para um seu entendimento como pensamento débil fazendo-se forte, uma razão institucional que no fundo em muitos casos é razão crítica, e convoca mesmo, quiçá, até o ácido cínico ${ }^{8}$.

\subsection{Interdisciplinaridade(s)}

No contexto complexo e de algum modo esquizofrénico da realidade do Direito, como interpretar o contributo da interdisciplinaridade? Melhor se diria, realmente, no plural, interdisciplinaridades, pois sob essa designação se abrigam bem diferentes realidades. Desde

7 Como diz VALÉRY, Paul - Introduction à la méthode de Léonard de Vinci, Paris, Nouvelle revue française, 1919, p. 18: “Léonard de Vinci n'a pas de rapport avec ces désordres. Parmi tant d'idoles que nous avons à choisir, puisqu'il en faut adorer au moins une, il a fixé devant son regard cette Rigueur Obstinée, qui se dit elle-même la plus exigeante de toutes".

${ }^{8}$ HOLMES, Oliver Wendell - The Path of Law, 1897, trad. cast. de E. A. Ruso, La Senda del Derecho, Buenos Aires, Abeledo Perrot, 1975, máx. pp. 18-21.

REDESG / Revista Direitos Emergentes na Sociedade Global - www.ufsm.br/redesg v. 3, n. 1, jan.jun/2014 
logo, recordaremos, sem desenvolver, que interdisciplinaridade não é multidisciplinaridade, nem transdisciplinaridades, que funcionam como pontes de certas disciplinas para certas outras, sem que verdadeiramente nenhuma saia do seu casulo, funcionando o "outro" epistemológico em grande medida como um pretexto de menor rigor na própria casa do saber, ou, quiçá mais frequentemente ainda, como uma flor na botoeira sem reais consequências. Há, pois, um certo "folclore" ou "fogo de vista" pseudo-interdisciplinar, que usa exemplos, e até métodos de outras racionalidades e horizontes teóricos como pretexto, moda, ou mesmo como cortina de fumo. 0 caso Sokal parece disso ter sido paradigmático?.

Por outro lado, há também interdisciplinaridades que (e isso era inesperado e por isso se afigura tão revoltante) se não fundam em afinidades reais ou hipóteses fecundas, ainda que arriscadas, mas que se encontram funcionalizadas, dependentes de razões que, dir-se-ia, $a$ própria razão desconhece. Referimo-nos à instrumentalização ou manipulação da interdisciplinaridade, que funciona então como álibi para alguns dos mais perversos processos de amputação universitária: em nome dela se fundem cadeiras, se hibridizam centros de pesquisa, se criam cursos de banda não se sabe mais se larga se afinal estreita ${ }^{10}$.

Mas se há interdisciplinaridades falsas e superficiais e interdisciplinaridades perversas, de mero pretexto institucional, umas e outras fenómenos recuperadores de um paradigma revolucionário e essencial para os saberes, que não mais podem funcionar de costas voltadas uns para os outros, como membra disjecta, também há interdisciplinaridades fecundas, que potenciam as capacidades heurísticas e alargam os limites das epistemai: que somam, que multiplicam, que problematizam, e assim fazem o mundo "pular e avançar" como na Pedra Filosofal de Manuel Freire.

\subsection{Interdisciplinaridade e Direito}

\subsubsection{Justaposição de saberes}

O Direito é, em si mesmo, filosofia prática, como logo viram os romanos, e tradução universal. Não sendo em si muito interdicisplinar, na sua versão positivista ainda muito difundida e hegemónica no ensino, o que constitui um contrasenso clamoroso, é contudo suscetível de com

\footnotetext{
9 SOKAL Alan / BRICMONT, Jean - Impostures intellectuelles, Odile Jacob, 1997. Cf. ainda, v.g., http://www.physics.nyu.edu/faculty/sokal/transgress_v2/transgress_v2_singl

${ }^{10}$ MORAN, Joe - Interdisciplinarity, Londres e Nova lorque, Routledge, 2002.

REDESG / Revista Direitos Emergentes na Sociedade Global - www.ufsm.br/redesg v. 3, n. 1, jan.jun/2014
} 
alguma facilidade poder convocar saberes-outros. Os que relevam do conhecimento da sociedade ou de ciências imediatamente "auxiliares" ou, melhor dito, complementares, dos diversos ramos jurídicos são os mais bem aceites, ainda que não tenham frequentemente expressão significativa nos curricula escolares.

Ninguém negará que o Direito Constitucional necessita de Filosofia Política e de Politologia, que o Direito Administrativo necessita de Ciência da Administração, que o Direito Penal só ganha com o conhecimento da Criminologia, que o Direito Comercial certamente terá interesse em noções económicas de Comércio e Contabilidade, etc.

E todas as disciplinas ganham com o estudo sociológico, geral e particular, do setor ou setores da sociedade que com elas mais convivem (ou vice-versa). Já em 1911, um ano após a implantação da República em Portugal, o legislador seria tentado a uma reforma dos estudos jurídicos muito interessante (embora gorada), pela qual o estudo das diversas matérias jurídicas proprio sensu seria precedido da formação sociológica respetiva. Era, evidentemente, o fruto do pensamento positivista então imperante, mas não parece que, no caso, fosse um erro. E seria excelente se tal conhecimento sociológico prévio viesse a ser temperado com a filosofia respetiva. Portanto, nem só Sociologia Criminal como introdução ao Direito Penal, mas também Filosofia Penal (e hoje, naturalmente, também Biologia Criminal, eu Neurociências no atinente a matéria de vontade e voluntariedade, consciência, como essenciais elementos para aquilatar desse complexo e vital conceito de "culpa”).

Mas esse é como que um primeiro nível, superficial ainda e de grande exterioridade, nos contactos jurídicos interdisciplinares.

\subsubsection{Hibridização de Saberes}

O triunfo da interdisciplinaridade no Direito passa por outros caminhos ainda, sem prejuízo deste, que vimos de referir, dever ser cultivado e aprofundado. Não há, pois, guerra entre dimensões interdisciplinares, mas complementaridade, e graus de aprofundamento.

Uma importante modalidade interdisciplinar, no Direito, é a que decorre da própria criação de disciplinas jurídicas (na maior parte dos casos jurisfilosóficas, ou associadas normalmente à Filosofia do Direito). Não são elas assepticas, muito pelo contrário, transportam consigo boa parte da racionalidade e da ideologia dominante nas áreas que com o Direito se hibridizam. Assim, a Análise Económica do Direito pode ser acusada de algum economicismo, tal 
como os estudos de Direito \& Literatura normalmente (se na sua fase mais avançada, não da simples procura de temas jurídicos em obras literárias) serão críticos, e não há como deixar de encontrar feminismo na Jurisprudência (ou Filosofia do Direito) Feminista.

\subsubsection{Perspetivação Jurídica Holística}

Mas falta referir ainda uma dimensão interdisciplinar fulcral. É a que resulta do pensar o Direito, tanto na sua dimensão filosófica como na criação e crítica do direito positivo, com instrumentos de análise provindos de todos os saberes que temos à nossa disposição. Não é um processo de agravar a "impureza" do Direito: o Direito nunca foi puro" ${ }^{11}$ Do que se trata é de simplesmente não fechar os olhos e os ouvidos a tudo o que pode instruir o Direito sobre a realidade (em todas as suas múltiplas dimensões), ajudá-lo a aperfeiçoar-se e a melhor cumprir o seu fim de caminho para a efetivação da Justiça.

Estamos perante a opção pela inserção do Direito na vastíssima República do Saber (não apenas República das Letras). Obviamente, o protagonista e observador tem de continuar, no caso, a ser o Direito. Não se dilui a sua identidade. Contudo, ele está necessariamente atento a tudo o que se faz como cultura, como expressão, como arte, como saber. Nihil humanii... - lema de Protágoras, de Terêncio, de Marx: nada do que é humano nos pode ser alheio.

A perspetivação interdisciplinar holística em Direito implica que ele considere todas as fontes possíveis (e credíveis) para a sua própria reconstrução problemática e crítica, pluralista.

\subsubsection{Interdisciplinaridade Jurídica Crítica}

Mas, ao contrário de outras démarches, não se trata (não deve, não pode tratar-se) de um fenómeno como os explicitados no início deste estudo. Ou seja, este holismo interdisciplinar tem de ser o exato simétrico dos procedimentos recuperadores, e forma de superação do conservadorismo jurídico.

Pode efetivamente haver práticas pseudo-interdisciplinares superficiais (como as aqui primeiramente recordadas) recuperadoras, conservadoras, solidárias de um discurso legitimador

\footnotetext{
11 As tentativas de Kelsen, tais como os anelos dos realistas clássicos, tão diferentes entre si, mas confluentes na busca dessa miragem, foram votadas ao fracasso, precisamente para que uns e outros pudessem - e legitimamente - salvar os respetivos pontos de vista de fundo.

REDESG / Revista Direitos Emergentes na Sociedade Global - www.ufsm.br/redesg v. 3, n. 1, jan.jun/2014
} 
do ilegítimo. Mas o próprio conceito de interdisciplinaridade que propomos, uma interdisciplinaridade madura e plena, implica o holismo e a crítica.

\subsubsection{Interdisciplinaridade Exógena e Interdisciplinaridade Endógena}

É patente o caráter exterior, exógeno (aqui no sentido de ter criação exterior, e de viver de uma grande exterioridade - caráter superficial) da interdisciplinaridade folclórica, que usa a outra racionalidade, a outra metodologia, o outro tópico como flor na botoeira, como artificio de erudição. Mas o verdadeiro contrário dessa orientação - que, insistimos, não é verdadeiramente interdisciplinar, até pela intencionalidade, pelo animus com que é empreendida - será uma interdisciplinaridade a que chamaríamos endógena.

Como entendê-la? Desde logo, porquê endógena? Endógena porque gerada de dentro. É uma preocupação e uma atividade doravante considerada "normal" na própria episteme que a assume, neste caso o Direito. Em vez de ser um esforço de uma disciplina que se "debruça” sobre outra(s) - lembrando uma fórmula de Hervé Bazin ${ }^{12}$ a um propósito afinal de algum modo paralelo, o da adesão ideológica, ou da opção de classe -, trata-se agora de um saber que se compreende como parte de um todo complexo e plural de saberes, e que, portanto, se afirma ao ir buscar o que interessa, aonde quer que se encontre, como recomendava Van de Velde.

Haverá mesmo alguma incorporação de conhecimentos e métodos até então considerados alheios, alienígenas, quiçá mesmo hostis.

Partirá de dentro esta nova fase e entendimento da Interdisciplinaridade. Com uma sinceridade e capacidade de acolhimento do "outro" epistémico, sem preconceitos, sobretudo sem arrogância. Arrogância de onde derivam as clássicas epistemomaquias, guerras mais ou menos fratricidas por disputa de terreno entre os saberes, normalmente saberes próximos.

\subsubsection{Novos Rumos}

É a superação de isolacionismos (em grande medida feitos de vaidades e invejas ${ }^{13}$ ) que se revela necessária para uma sã e produtiva colaboração entre disciplinas, e entre oficiais do

\footnotetext{
${ }^{12}$ BAZIN, Hervé - La mort du petit cheval, Paris, Grasset, 1950, trad. port., A Morte do Cavalinho, Lisboa, Editores Associados, s.d..

${ }^{13}$ GILLMAN, Dr. Mark A. - Envy as a Retarding Force in Science, Aldershot/Brookfield, USA/Hong Kong et all., Avebury, 1996.

REDESG / Revista Direitos Emergentes na Sociedade Global - www.ufsm.br/redesg v. 3, n. 1, jan.jun/2014
} 
mesmo de de outros ofícios. No fundo, é a substituição da velha Universidade da cátedra enquistada, da professia professoral weberiana, da intriga, do favoritismo, do veneno e do punhal, por uma Universidade bem diversa.

Oxalá alguns dos novos ao menos não caiam no mimetismo dos antigos (para mais agravado pelo niilismo presente, que não conhece limites), e se dediquem a um Novo Direito, servido por uma Nova Pedagogia Jurídica, que implica uma nova Deontologia docente.

\section{REFERÊNCIAS}

BAPTISTA PEREIRA, Miguel - Crise e Crítica, in "Vértice“, vol. XLIII, n. ${ }^{4} 456 / 7$, Coimbra, SetembroDezembro de 1983.

BATISTA MACHADO, João - Introdução ao Direito e ao discurso legitimador, reimp., Coimbra, Almedina, 1985.

BAZIN, Hervé - La mort du petit cheval, Paris, Grasset, 1950, trad. port., A Morte do Cavalinho, Lisboa, Editores Associados, s.d.

Cf. FIX-FIERRO, Héctor - “Presentación” de Eduardo García Máynez (1908-1993). Vida y obra, de Imer B. Flores, México, Universidad Nacional Autónoma de México, 2007, p. XI.

DEBORD, Guy - La société du spectacle, Paris, Gallimard, 1992.

GILLMAN, Dr. Mark A. - Envy as a Retarding Force in Science, Aldershot/Brookfield, USA/Hong Kong et all., Avebury, 1996.

HOLMES, Oliver Wendell - The Path of Law, 1897, trad. cast. de E. A. Ruso, La Senda del Derecho, Buenos Aires, Abeledo Perrot, 1975.

MORAN, Joe - Interdisciplinarity, Londres e Nova lorque, Routledge, 2002.

SOKAL Alan / BRICMONT, Jean - Impostures intellectuelles, Odile Jacob, 1997. Cf. v.g., http://www.physics.nyu.edu/faculty/sokal/transgress_v2/transgress_v2_singl.

VALÉRY, Paul - Introduction à la méthode de Léonard de Vinci, Paris, Nouvelle revue française, 1919.

WARAT, Luis Alberto - O Ofício do Mediador, Florianópolis, Fundação Boiteux, 2004. 